\title{
Rabbit somatic cell cloning: effects of donor cell type, histone acetylation status and chimeric embryo complementation
}

\author{
Feikun Yang, Ru Hao, Barbara Kessler, Gottfried Brem, Eckhard Wolf and Valeri Zakhartchenko \\ Department of Molecular Animal Breeding and Biotechnology, Ludwig-Maximilians University Munich, \\ Hackerstrasse 27, 85764 Oberschleissheim, Germany and ${ }^{1}$ Agrobiogen GmbH, 86567 Hilgertshausen, Germany
}

Correspondence should be addressed to V Zakhartchenko; Email: v.zakhartchenko@gen.vetmed.uni-muenchen.de

\begin{abstract}
The epigenetic status of a donor nucleus has an important effect on the developmental potential of embryos produced by somatic cell nuclear transfer (SCNT). In this study, we transferred cultured rabbit cumulus cells (RCC) and fetal fibroblasts (RFF) from genetically marked rabbits (Alicia/Basilea) into metaphase II oocytes and analyzed the levels of histone H3-lysine 9-lysine 14 acetylation (acH3K9/14) in donor cells and cloned embryos. We also assessed the correlation between the histone acetylation status of donor cells and cloned embryos and their developmental potential. To test whether alteration of the histone acetylation status affects development of cloned embryos, we treated donor cells with sodium butyrate ( $\mathrm{NaBu}$ ), a histone deacetylase inhibitor. Further, we tried to improve cloning efficiency by chimeric complementation of cloned embryos with blastomeres from in vivo fertilized or parthenogenetic embryos. The levels of acH3K9/14 were higher in $\mathrm{RCCs}$ than in $\mathrm{RFFs}(P<0.05)$. Although the type of donor cells did not affect development to blastocyst, after transfer into recipients, RCC cloned embryos induced a higher initial pregnancy rate as compared to RFF cloned embryos (40 vs $20 \%)$. However, almost all pregnancies with either type of cloned embryos were lost by the middle of gestation and only one fully developed, live RCC-derived rabbit was obtained. Treatment of RFFs with $\mathrm{NaBu}$ significantly increased the level of acH3K9/14 and the proportion of nuclear transfer embryos developing to blastocyst (49 vs $33 \%$ with non-treated $\mathrm{RFF}, \mathrm{P}<0.05$ ). The distribution of acH3K9/14 in either group of cloned embryos did not resemble that in in vivo fertilized embryos suggesting that reprogramming of this epigenetic mark is aberrant in cloned rabbit embryos and cannot be corrected by treatment of donor cells with NaBu. Aggregation of embryos cloned from NaBu-treated RFFs with blastomeres from in vivo derived embryos improved development to blastocyst, but no cloned offspring were obtained. Two live cloned rabbits were produced from this donor cell type only after aggregation of cloned embryos with a parthenogenetic blastomere. Our study demonstrates that the levels of histone acetylation in donor cells and cloned embryos correlate with their developmental potential and may be a useful epigenetic mark to predict efficiency of SCNT in rabbits.

Reproduction (2007) 133 219-230
\end{abstract}

\section{Introduction}

In view of the major relevance of genetically modified rabbits as animal models of human diseases and as small, but fast bioreactors for the production of therapeutic proteins, SCNT from genetically engineered donor cells would be of outstanding importance in this species. However, low efficiency of SCNT in all species studied so far greatly hindered its application in biomedicine and agriculture. As one of the key factors, the type of nuclear donor cell, which is characterized by origin and extent of differentiation, has a significant effect on the efficiency of nuclear transfer and the development of reconstructed embryos. Among the somatic cell types tested for nuclear transfer, cumulus cells appear to be the best choice with the highest cloning efficiency and the least proportion of abnormalities in cloned animals (Tian et al. 2003). Whereas, diverse animal species have been cloned from different types of cultured donor cells (Wilmut et al. 1997, Kato et al. 1998, Baguisi et al. 1999, Polejaeva et al. 2000, Wakayama \& Yahagimachi 2001, Galli et al. 2003, Shin et al. 2002, Woods et al. 2003, Zhou et al. 2003, Lee et al. 2005), in rabbits, first live cloned offspring could be produced only from freshly prepared cumulus or oviductal cells (Chesne et al. 2002, Inoue et al. 2002, Challah-Jacques et al. 2003), and cloning from cultured cells fibroblasts resulted only in implantation or early fetal development (Yin et al. 2000). However, for the purpose of generating transgenic rabbits by SCNT, donor cells must be cultured for transfection and selection to facilitate the required genetic modification. Rabbit 
cumulus cells are relatively difficult to maintain in longterm culture (Dinnyes et al. 2001), and thus stable transfected cell clones cannot be readily established. Fetal fibroblasts, which grow rapidly and have the potential for many cell divisions in culture (Schnieke et al. 1997, Cibelli et al. 1998, McCreath et al. 2000), have been widely used for transgenesis via SCNT, including gene targeting (Denning \& Priddle 2003, Kuroiwa et al. 2004).

Only recently, Li et al. (2006) reported production of cloned rabbits from cultured adult fibroblasts using a 'novel' SCNT protocol involving minor modifications of the previously established SCNT technique (Chesne et al. 2002). However, from a total 14 born cloned rabbits 9 died shortly after birth. Because of a predominantly stochastic nature of nuclear reprogramming, it is more likely that even with improved SCNT technique clones may not be free of epigenetic errors.

There is increasing evidence that successful reprogramming of a donor nucleus after transfer into a recipient cytoplast is largely dependent on its epigenetic state and can be influenced by in vitro culture conditions, including passage number, serum concentration, cell density, and physical/chemical treatment (Enright et al. 2003a, 2003b, Shi et al. 2003a). Major epigenetic characteristics of donor cells are DNA methylation and histone modifications (Shi et al. 2003b). Previous studies have linked developmental defects in cloned embryos to aberrant epigenetic reprogramming during early development (Dean et al. 2001, Kang et al. 2001, 2003) and proposed epigenetic modifications to the chromatin of donor cells, DNA methylation and histone H3K9 methylation, as reasonable marks of nuclear reprogramming, which correlate with developmental potential of cloned embryos (Santos et al. 2003). Another epigenetic modification, histone acetylation, which is closely associated with DNA and histone methylation, is involved in diverse cellular functions and processes, and may function as an epigenetic mark, a histone code, by which information about genomic function is transmitted from one generation of cells to the next (Turner 2000). Acetylated form of the histone H3-lysine 9-lysine $14(\mathrm{acH} 3 \mathrm{~K} 9 / 14)$ is associated with active (euchromatin and facultative heterochromatin) chromatin configuration (Rice \& Allis 2001). Staining with an antibody to acH3K9/14 can be used as a measure of euchromatic characteristics in the early embryo. Following nuclear transfer (NT), the histone acetylation status of the donor nucleus, which must be reprogrammed to an embryonic one, is affected by a number of factors and can be experimentally manipulated. For example, histone acetylation levels in bovine cumulus and fibroblast cells were shown to be affected by the stage of the cell cycle, cell origin, and cell passage numbers (Enright et al. 2003a). Moreover, global histone acetylation in donor cells could be increased by treatment with histone deacetylase (HDAC) inhibitor, trichostatin A
(Enright et al. 2003b). Treatment of donor cells with chromatin modifying agents may improve their ability to be reprogrammed by a recipient cytoplast. Kishigami et al. (2006) demonstrated that trichostatin treatment leads to more than fivefold increase in success rate of mouse cloning from cumulus cells without obvious abnormalities. Previously, we demonstrated that treatment of bovine fetal fibroblasts with sodium butyrate $(\mathrm{NaBu})$, another HDAC inhibitor, resulted in a more than twofold increase in the rate of cloned blastocysts compared with that of untreated cells (Shi et al. 2003a). Little is known as to epigenetic reprogramming in rabbits. The absence of demethylation during early development correlated with low rabbit cloning efficiency (Shi et al. 2004). The histone acetylation status of rabbit somatic cells, which may also contribute to a low cloning efficiency in this species, has not been studied so far.

A potential approach to improve the developmental competence of cloned embryos is aggregation with non-cloned embryonic cells. There is evidence for metabolic cooperation between cell types of different genetic origin through permeable cell junctions that enable metabolically deficient cells to function in a normal manner (Pitts \& Burk 1976). Developing intercellular junctions between blastomeres of different origin might play a role in communication and subsequently enhance development of the chimeric embryos (Ducibella \& Anderson 1975).

In the present study, we investigated the levels of acH3K9/14 in two types of donor cells, cumulus cells (RCC) and fetal fibroblasts (RFF), and the dynamic of acH3K9/14 immunofluorescence distribution in the corresponding cloned embryos. We assessed whether the histone acetylation status of donor cells and cloned embryos correlates with their developmental potential. We also tested the effects of modification of acH3K9/14 levels in donor cells using treatment with an inhibitor of HDACs and tried to improve in vivo development of cloned embryos by their aggregation with blastomeres of in vivo fertilized or parthenogenetic embryos.

\section{Materials and Methods}

Animal experiments were approved by the Ethical Committee for Animal Experimentation of the University of Munich and were performed in accordance with the European Union Normative for Care and Use of Experimental Animals.

Unless otherwise indicated, all chemicals were purchased from Sigma Chemical Co.

\section{Recipient oocyte collection}

Oocytes were obtained from sexually mature out bred Zika rabbits (approximately $3.0 \mathrm{~kg}$ and more than 6 months old). All experiments were carried out during the 
natural breeding season. Female rabbits were superovulated by injection of $100 \mathrm{IU}$ pregnant mares serum gonadotrophin (Intergonan, Intervet, Unterschleissheim, Germany) intramuscularly and 100 IU human chorionic gonadotrophin (hCG; Ovogest, Intervet) intravenously $72 \mathrm{~h}$ later. Mature oocytes were flushed from the oviducts 15-16 h post-hCG injection in warm phosphate buffered saline (PBS) supplemented with $4 \mathrm{mg}$ bovine serum albumin $\mathrm{ml}^{-1}$ (BSA). Cumulus cells were removed by gentle pipetting with a small-bore pipette after treatment of oocytes with $5 \mathrm{mg} / \mathrm{ml}$ hyaluronidase in M199 (Medium 199 supplemented with $10 \%$ fetal calf serum (FCS) for $15 \mathrm{~min}$ at $38.5{ }^{\circ} \mathrm{C}$.

\section{Induction of metaphase II protrusion and enucleation}

Denuded oocytes were treated with $0.6 \mu \mathrm{g}$ demecolcine $\mathrm{ml}^{-1}$ between $40 \mathrm{~min}$ and $2 \mathrm{~h}$ (Yin et al. 2002). The resulting metaphase II protrusion with little underlying cytoplasm was removed in M199 supplemented with $7.5 \mu \mathrm{g}$ cytochalasin $\mathrm{B} \mathrm{ml}^{-1}$ (CB) and $0.6 \mu \mathrm{g}$ demecolcine $\mathrm{ml}^{-1}$ using an enucleation pipette. Enucleated oocytes were kept in M199 and later used as recipient cytoplasts.

\section{Preparation of somatic donor cells}

Heterozygous Alicia (Ali)/Basilea (Bas) rabbits, donated by Therapeutic Human Polyclonals, Inc., (Sunnyvale, CA, USA) were used as donors of somatic cells. Ali is a rabbit strain, which has a variant of the allotype allele a2 associated with the $\mathrm{H}$ chain of immunoglobulin molecules. Bas is another rabbit strain with a mutant gene at the $\mathrm{Ab}$ allotypic locus controlling the synthesis of allotypic specificities (Ab4, Ab5, Ab6, Ab9, Ab4v, and Ab95) of $\kappa$-immunoglobulin light chains (Garcia et al. 1982, Kelus \& Weiss 1986).

\section{Rabbit cumulus cells (RCC)}

In vivo matured oocytes (Ali/Bas) were collected from superovulated donors. Cumulus cells were recovered from cumulus-oocyte complexes after hyaluronidase treatment, pooled, and cultured in Dulbecco modified Eagle medium (DMEM) supplemented with 10\% (v/v) FCS, $2 \mathrm{mmol} / \mathrm{l}$ pyruvic acid, $2 \mathrm{mmol} / \mathrm{l}$ L-glutamine, $0.1 \mathrm{mmol} / \mathrm{l}$ 2-mercaptoethanol, $2 \mathrm{mmol} / \mathrm{l}$ non-essential amino acids, $100 \mathrm{IU}$ penicillin $\mathrm{ml}^{-1}$, and $100 \mu \mathrm{g}$ streptomycin $\mathrm{ml}^{-1}$ in a humidified atmosphere of $5 \%$ $\mathrm{CO}_{2}$ in air at $38.5{ }^{\circ} \mathrm{C}$. Confluent cells at passages $1-5$ were used as nuclear donors.

\section{Rabbit fetal fibroblasts (RFF)}

Fetal fibroblasts were established from an individual Ali/Bas female fetus 15 to 16 days post-coitum and cultured in DMEM. Confluent fetal fibroblasts from passages 1 to 8 were either directly used as donors for NT (RFF) or split as 1:4 of their confluent density and then treated with $1 \mathrm{mmol} / \mathrm{N} \mathrm{NaBu}$ prepared in cell culture medium for $72 \mathrm{~h}$ (RFF-NaBu cells). After 3 days of culture, RFF-NaBu cells reached $80-90 \%$ confluence and were larger than non-treated RFFs.

Prior to nuclear transfer, attached cells were trypsinized, and suspended in M199 after three times wash.

\section{Detection of histone acetylation levels in donor cells}

Confluent RCCs at passage 3, and RFFs and RFF-NaBu cells at passage 5 were used to evaluate their histone acetylation levels. Proteins were prepared by acid extraction. Adherent cells were washed three times with ice-cold PBS, scraped from the culture dish and collected by centrifugation at $1200 \mathrm{~g}$ for $10 \mathrm{~min}$. The washed cells were suspended in $1 \mathrm{ml}$ of ice-cold lysis buffer $(10 \mathrm{mmol} / \mathrm{I}$ Tris- $\mathrm{HCl}, 50 \mathrm{mmol} / \mathrm{l}$ sodium bisulfite, 1\% Triton X-100, $10 \mathrm{mmol} / \mathrm{I} \mathrm{MgCl}_{2}, 8.6 \%$ sucrose, $\mathrm{pH}$ 6.5) and homogenized by passing them 20 times through a 20-gauge needle. The nuclei were collected by centrifugation at $1200 \mathrm{~g}$ for $10 \mathrm{~min}$, washed three times with lysis buffer, and once with TE (Tris-HCl/EDTA) buffer (10 mmol// Tris- $\mathrm{HCl}, 13 \mathrm{mmol} / \mathrm{l}$ EDTA, $\mathrm{pH}$ 7.4). The pellet was suspended in $0.1 \mathrm{ml}$ of ice-cold autoclaved $\mathrm{H}_{2} \mathrm{O}$ using a Vortex mixer, and concentrated $\mathrm{H}_{2} \mathrm{SO}_{4}$ was added to the suspension to a final concentration of $0.2 \mathrm{~N}$, followed by incubation at $4{ }^{\circ} \mathrm{C}$ overnight. After centrifugation for $5 \mathrm{~min}$ at $1200 \mathrm{~g}$, the supernatant was mixed well with $1 \mathrm{ml}$ of acetone in a new Eppendorf tube, and then incubated at $-20{ }^{\circ} \mathrm{C}$ overnight. Coagulated material was collected by centrifugation for $5 \mathrm{~min}$ at highest speed and the pellet was allowed to air dry. The acid soluble histone fraction was dissolved in $50 \mu \mathrm{l}$ of autoclaved $\mathrm{H}_{2} \mathrm{O}$. Protein was quantified using Bradford Reagent, and Varian u.v.-visible spectrometer (Cary WinUV 50Bio, Varian, Darmstadt, Germany) was used to measure the absorbance at $595 \mathrm{~nm}$.

Ten micrograms of protein were loaded on 15\% SDSpolyacrylamide gels. Proteins were blotted onto PVDF membrane (Millipore, Eschborn, Germany). Histone acetylation was investigated by Western immunoblot analysis. Primary antibodies were goat-anti-acetylated histone H3 (Lys 9/14) (sc-8655; Santa Cruz Biotechnology, Heidelberg, Germany; dilution 1:350). Bound antibodies were detected by using donkey antigoat IgG-AP (sc-2310; Santa Cruz Biotechnology; dilution 1:500). Detection of bound secondary antibodies was performed by developing the membrane with 5-bromo-4-chloro-3-indolyl phosphate/nitro blue tetrazolium (BCIP/NBT) blue liquid substrate membrane detection solution in a dark room. As control, cells were incubated with primary or secondary antibodies alone.

\section{Nuclear transfer, fusion and activation}

Transfer of donor karyoplast was carried out essentially as described previously (Zakhartchenko et al. 1999). 
Briefly, an individual nuclear donor cell was introduced under the zona pellucida of enucleated oocyte in M199. Karyoplast-cytoplast complexes (KCC) were manually aligned in a fusion chamber consisting of two wire electrodes $200 \mu \mathrm{m}$ apart, overlaid with Eppendorf fusion medium and then fused with an Eppendorf Multiporator (Hamburg, Germany) using double direct current of $1.95 \mathrm{kV} / \mathrm{cm}, 25 \mu \mathrm{s}$. After 20-40 min incubation in M199, fused KCC were activated by the same electric pulses as for fusion, then immediately incubated for $1 \mathrm{~h}$ in $1.9 \mathrm{mmol} / \mathrm{l}$ 6-dimethylaminopurine and $5 \mu \mathrm{g} \mathrm{CB} \mathrm{ml}-1$ prepared in Menezo B2 medium (INRA, Paris, France) containing $10 \%$ FCS in a humidified atmosphere of $5 \%$ $\mathrm{CO}_{2}$ in air at $38.5{ }^{\circ} \mathrm{C}$.

\section{Detection of acH3K9/14 immunofluorescence in in vivo fertilized and cloned embryos}

In vivo fertilized and cloned embryos, which were freed of zona pellucida at desired stages, were washed three times in PBS, fixed for $15 \mathrm{~min}$ in $4 \%$ paraformaldehyde in PBS, and permeabilized with $0.2 \%$ Triton $X-100$ in PBS for $30 \mathrm{~min}$ at room temperature. After washing with $0.1 \%$ Triton X-100 and 0.1\% Tween-20 in PBS, embryos were blocked overnight at $4{ }^{\circ} \mathrm{C}$ in $1 \%$ BSA and $0.05 \%$ Tween20 in PBS (blocking solution), then incubated with goatanti-acetylated histone $\mathrm{H} 3$ (Lys 9/14) antibody in fresh blocking buffer overnight at $4{ }^{\circ} \mathrm{C}$. After thorough wash in fresh blocking buffer, embryos were incubated with donkey anti-goat IgG-APantibody in fresh blocking buffer for $1 \mathrm{~h}$ at room temperature. Embryos were washed again and transferred in minimum volume of blocking solution into $6 \mu \mathrm{l}$ Vectashield mounting medium with 4', 6-diamino-2-phenylindole (DAPI) (Vector laboratories, Grünberg, Germany). Observations were performed with a fluorescent microscope (Axiovert 200M; Zeiss, Hallbergmoos, Germany). Images were recorded digitally with a high-resolution CCD camera under identical exposure time. Six to fifteen embryos were analyzed per each stage of development. As control, embryos were incubated with primary or secondary antibodies alone. Both normal and cloned embryos as well as all embryos at different stages were stained simultaneously to reduce experimental variability.

\section{Embryo culture and transfer}

After activation, reconstructed embryos were cultured overnight in $\mathrm{B} 2$ medium at $38.5{ }^{\circ} \mathrm{C}$ and $5 \% \mathrm{CO}_{2}$ in air. Using the laparoscopic technique described by Besenfelder \& Brem (1993), 4- to 10-cell stage cloned embryos were transferred through the infundibulum into each oviduct of recipient females which were induced into pseudopregnancy status either by mating to vasectomized males or injection of $80 \mathrm{IU}$ hCG at 20-22 h after injecting the females used as oocyte donors. Pregnancy was determined by palpation around 2 weeks after embryo transfer. To assess the developmental potential to blastocyst, cloned embryos were cultured in B2 medium for up to 6 days. As control for embryo transfer technique, 4- to 10-cell stage in vivo fertilized embryos were transferred into recipients and either flushed on day 5 after transfer or left to determine pregnancy and offspring rates.

\section{Chimeric embryo complementation}

To improve in vivo development of embryos cloned from $\mathrm{NaBu}$-treated cells, we aggregated them with blastomeres of in vivo fertilized or parthenogenetic embryos.

Superovulated Zika females were mated with fertile Zika males followed by i.v. injection with $100 \mathrm{IU}$ hCG. In vivo fertilized embryos were collected by flushing oviducts with mPBS $16 \mathrm{~h}$ after hCG injection, and then cultured in B2 medium. To prepare parthenogenetic embryos, cumulus-free oocytes were activated and cultured under the same conditions as used for nuclear transfer embryos.

Six- to 12-cell in vivo fertilized or parthenogenetic embryos were treated with $0.5 \%$ pronase in mPBS for seconds to remove the zona pellucida, and then incubated in $0.25 \%$ trypsin- $0.01 \%$ EDTA in mPBS for 2 min to separate individual blastomeres. A single or two blastomeres were introduced under the zona pellucida of 4- to 10-cell stage cloned embryos in M199

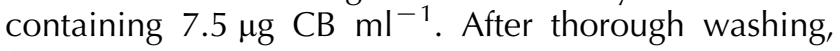
first in M199 and then in B2 medium, aggregation embryos were cultured in B2 medium either till embryo transfer within $1 \mathrm{~h}$ or up to 6 days for the assessment of development to blastocyst.

\section{Ali/Bas genotyping of fetuses and offspring}

Genomic DNA from nuclear donor cells as well as tissues from recipient animals, fetuses and offspring was extracted by using the QIAamp DNA Mini Kit (Qiagen). Due to the fact that the used wild-type rabbit strains belong to the e15 allotype (accession no. K00752), whereas Ali/Bas rabbits belong to the e14 allotype (Accession no. J00665), it was possible to unequivocally identify fetuses and offspring originating from SCNT. For determination of the 1-bp difference between e14 and e15 allotypes, which maps in the $\mathrm{CH} 2$ domain of the $\lg \mathrm{H}$ constant region, a specialized SNP genotyping kit (Genespector) was developed by Variom (Berlin, Germany). The principle of this oligonucleotide ligation assay is based on the mismatch sensitivity of T4 DNA ligase. In brief, two oligonucleotides specific for the e14 or e15 allele were coated to different wells of a 96-well microtiter plate. A biotinylated signal probe together with a PCR product comprising the e14/15 mismatch were added to the wells. The signal probe was linked to the coated oligonucleotide by T4 DNA ligase if the 
corresponding allotype was present in the PCR product. Visualization of the results was possible by addition of a streptavidin-peroxidase conjugate, detecting the linkage of the signal probe and catalyzing the processing of a substrate.

\section{Statistical analysis}

The proportions of embryos at each developmental stage were compared by $\chi^{2}$ analysis. Statistical differences for histone acetylation in donor nuclei were determined by using Student-Newman-Keulus' test. $P<0.05$ was considered as significant.

\section{Results}

\section{Histone acetylation status of donor cells prior to nuclear transfer}

Western blotting showed that the levels of acH3K9/14 were higher in RCCs than in RFFs $(P<0.05$; Fig. 1A and B). Compared to RCCs and non-treated RFFs, NaBu treatment significantly $(P<0.01)$ increased the level of acH3K9/14 in RFFs. Similar to the results obtained from Western blotting of donor cells, acetylation levels of histone H3K9/14 detected by immunostaining of reconstructed oocytes before artificial activation were higher in the nuclei of NaBu-treated RFFs (Fig. 1C). Fluorescence was not detected in control cells incubated with primary or secondary antibody alone (data not shown).

\section{Development of cloned embryos}

The differences in histone acetylation levels between RCC, RFF and RFF-NaBu donor cells suggest that the corresponding cloned embryos may also differ in their developmental potential. Although the cleavage rate of cloned embryos in the RCC group was lower $(P<0.05)$ than that in RFF group, their development to blastocyst was similar (Table 1). Treatment of RFFs with $\mathrm{NaBu}$
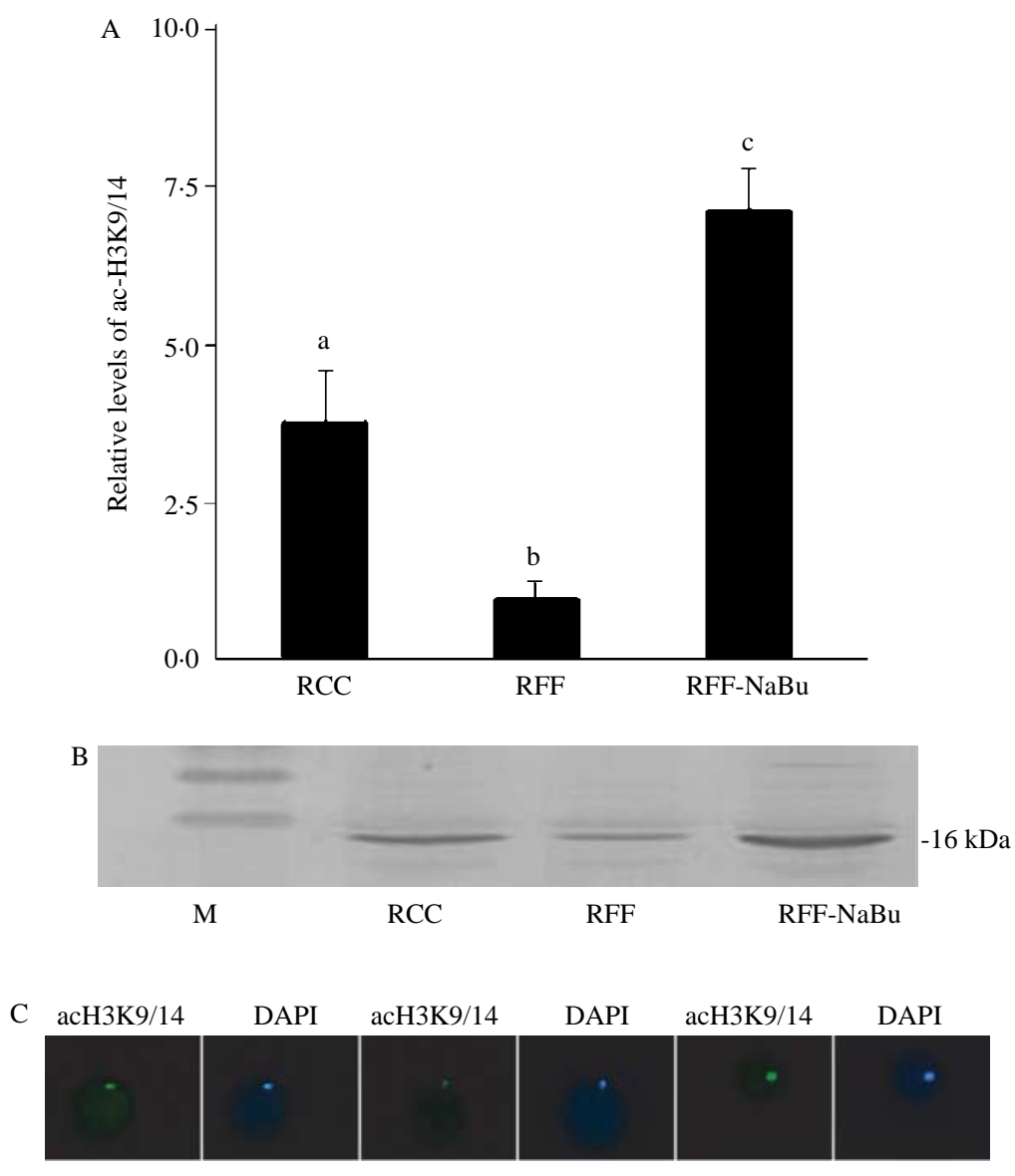

$\mathrm{RCC}$

RFF

RFF-NaBu

Figure 1 Histone H3K9/14 acetylation status of donor cells. (A) Relative levels of H3K9/14 acetylation in various types of cells prior to NT; RCC, cumulus cells; RFF, fetal fibroblasts; RFF-NaBu, fetal fibroblasts treated with NaBu. Data are expressed in relation to the RFF group. The diagram shows means and standard deviations (S.D.) from three independent experiments. Significant differences between donor cell types are indicated by different superscripts: a:b, $P<0.01$; a:c, b:c, $P<0.05$. (B) Representative Western blot; $10 \mu \mathrm{g}$ protein was loaded per lane; $M$, molecular weight marker. (C) Immunostaining of donor cells transferred into non-activated oocytes (1-1.5 h after transfer). Cells were immunostained with anti acH3K9/14 (green) and stained with DAPI for chromatin (blue). Images are at magnification $\times 400$. 
markedly $(P<0.05)$ improved the development of cloned embryos to blastocyst. Transfer of cloned embryos into recipients resulted in pregnancies in all groups. However, no recipients receiving RFF- or RFF$\mathrm{NaBu}$-derived embryos maintained pregnancy to term. From two pregnant recipients receiving RCC-derived embryos, one was euthanized on day 16 after embryo transfer and four implantation sites were found. From the other recipient, which suffered from a disease, one live pup was recovered by caesarean section on day 27 , and two additional concepti in resorption were found. The prematurely recovered pup died within $3 \mathrm{~h}$. Both the live pup and two concepti were identified to be genetically identical to nuclear donors.

\section{Development of in vivo fertilized embryos}

After transfer of 77 control in vivo fertilized embryos into four recipients, one recipient was euthanized on day 5 and 11 from 30 transferred embryos were flushed (37\%). Out of these 11 embryos, six (55\%) were growing blastocysts with the size from 750 to $2000 \mu \mathrm{m}$. These findings show that about $20 \%(6 / 30)$ of the transferred embryos were viable and could potentially develop further. Two of three recipients became pregnant and gave birth to nine live pups $(19 \%, 9 / 47)$.

\section{Histone acetylation status of in vivo fertilized and cloned embryos}

For successful development of cloned embryos, epigenetic status of donor cells must be reprogrammed to that of normal embryos. However, so far, it was unknown whether histone acetylation status of cloned rabbit embryos resembles that of normal embryos. Neither RCC-derived cloned embryos nor embryos cloned from RFF or RFF-NaBu cells were similar to normal embryos in respect to histone acetylation status. In vivo fertilized embryos became hypoacetylated at the 2- and 8-cell stages, with increases at the 4 -cell stage and after 16-cell stage (Fig. 2). At the morula and blastocyst stages in vivo fertilized embryos were hyperacetylated. RCC-derived cloned embryos displayed low levels of acH3K9/14 at the 1 - and 2-cell stages, with increases to moderate levels at the 4- to 16-cell stages and to high levels at the morula and blastocyst stages.

Embryos derived from RFFs were hyperacetylated at all stages except for the 4- and 8-cell stages with moderate and remarkably low acetylation levels respectively. In embryos cloned from RFF-NaBu cells histone acetylation signals were high at the 1- to 4-cell stages, almost undetectable at the 8-cell stage, with increases from low at the 16-cell stage to moderate and high at the morula and blastocyst stages respectively.

Fluorescence was not detected in control embryos incubated with primary or secondary antibody alone (data not shown).

\section{Effect of embryo aggregation}

Significantly higher $(P<0.05)$ blastocyst rates were obtained when embryos cloned from RFF-NaBu cells were aggregated with either one (cloned-1FB) or two (cloned-2FB) blastomeres of in vivo fertilized embryos as compared with non-aggregated cloned embryos (Table 2). One of six recipients receiving 191 cloned$1 F B$ aggregated embryos became pregnant, but no offspring was obtained. When 201 cloned-2FB aggregated embryos were transferred into five recipients, two of them became pregnant. To assess the origin of the fetuses, the pregnant recipients were euthanized on day 12 and day 13 after embryo transfer respectively. Two and three fetuses respectively, were found in resorption in the two recipients, but none of the fetuses had Ali/Bas genetic background.

When cloned embryos were aggregated with either one (cloned-1PB) or two (cloned-2PB) blastomeres of 6to 12-cell parthenogenetic embryos, only cloned-2PB aggregated embryos developed to blastocyst significantly better $(P<0.05)$ than non-aggregated cloned embryos. However, after transfer of 109 cloned-1PB aggregated embryos into three recipient mothers, two were diagnosed pregnant on day 14 after embryo transfer. From these two recipients, one lost the

Table 1 Development of rabbit embryos cloned from different types of somatic donor cells.

\begin{tabular}{|c|c|c|c|c|c|c|c|}
\hline \multirow[b]{2}{*}{ Nuclear donors } & \multirow[b]{2}{*}{$n$} & \multirow[b]{2}{*}{ Fused (\%) } & \multicolumn{2}{|c|}{ In vitro development } & \multicolumn{3}{|c|}{ In vivo development } \\
\hline & & & Cleaved (\%) & Blastocyst $(\%)^{\mathrm{a}}$ & $\begin{array}{l}\text { Embryos/ } \\
\text { recipients }\end{array}$ & Pregnancy & Offspring \\
\hline $\mathrm{RCC}$ & 8 & $392 / 427(92)^{*}$ & $269 / 341(79)^{*}$ & $32 / 95(34)^{*}$ & $172 / 5$ & $2 / 5$ & $1^{\mathrm{b}}$ \\
\hline RFF & 11 & $704 / 736(96)^{*+}$ & $611 / 650(94)^{\dagger}$ & $41 / 124(33)^{*}$ & $450 / 10$ & $2 / 10$ & 0 \\
\hline RFF-NaBu & 6 & $493 / 500(99)^{\dagger}$ & $457 / 469(97)^{\dagger}$ & $86 / 175(49)^{\dagger}$ & $271 / 7$ & $1 / 7$ & 0 \\
\hline
\end{tabular}

RCC, rabbit cumulus cell; RFF, rabbit fetal fibroblast; RFF-NaBu, sodium butyrate-treated RFF; some cleaved 4-10-cell stage embryos were transferred into recipient and some were let to form blastocysts in vitro; ${ }^{*}$ Values within the same column with different superscripts differ significantly $(P<0.05)$.

${ }^{a}$ Blastocyst rates were calculated based on the numbers of fused embryos. ${ }^{b}$ Data from two pregnant females: one was killed on day 16 , and the other one delivered by operation on day 27 after embryo transfer. 


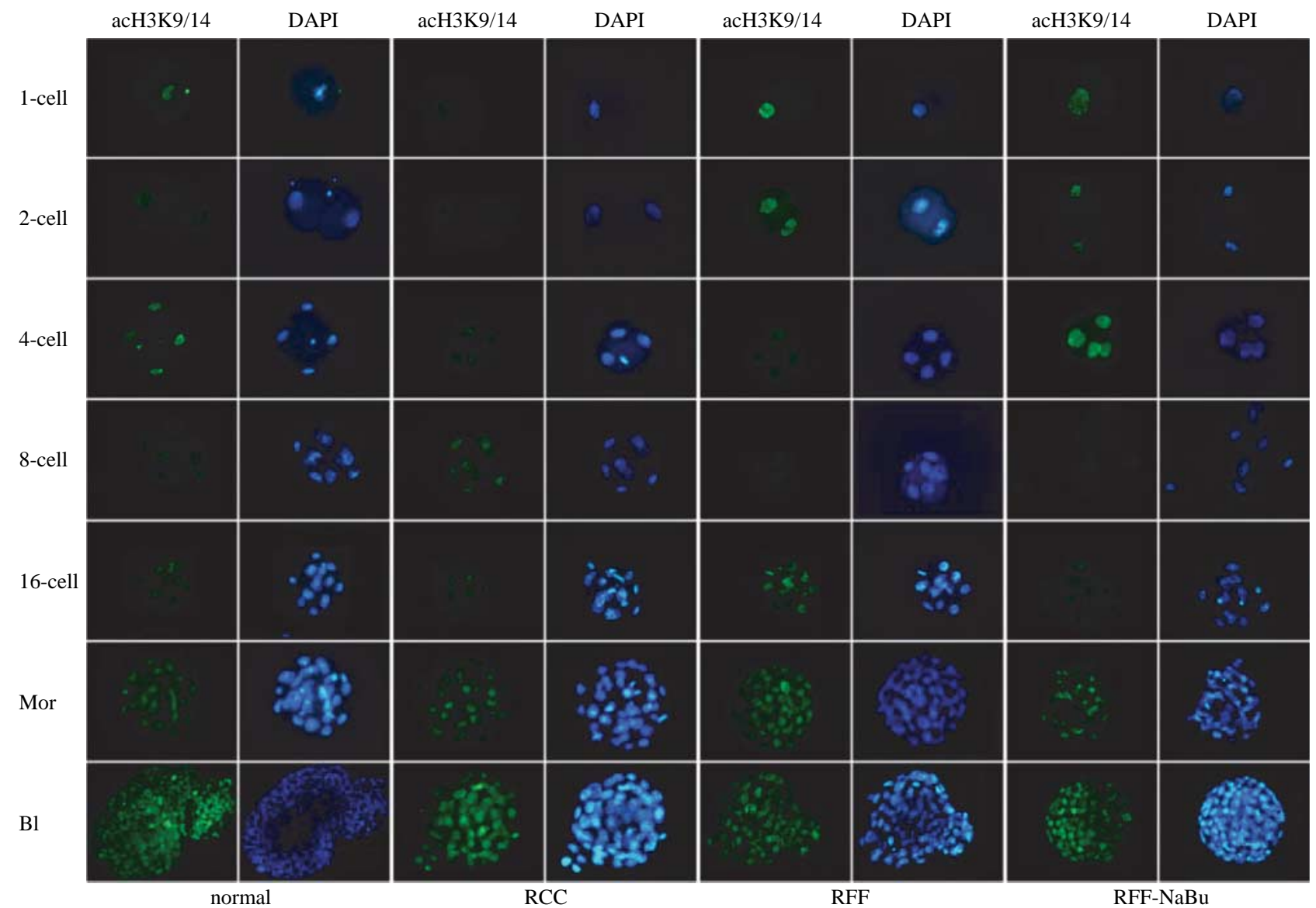

Figure 2 Histone acH3K9/14 status of in vivo fertilized and cloned embryos. Normal: in vivo fertilized embryos. RCC, RFF and RFF-NaBu, embryos cloned from cumulus cells, fetal fibroblasts and $\mathrm{NaBu}$-treated fetal fibroblasts respectively. Mor, morulae; Bl, blastocysts. In vivo fertilized 1-cell embryos (zygotes) were fixed 19-20 h post coitum. Cloned embryos from either group were fixed 3-4 h post activation. Cells were immunostained with anti-acH3K9/14 (green) and stained with DAPI for chromatin (blue). The images represent acH3K9/14 patterns as in the majority of stained embryos (Normal: 1-cell - 9/10, 2-cell - 13/13, 4-cell - 9/9, 8-cell - 15/15, 16-cell - 9/9, morulae - 11/11, blastocysts - 11/11; RCC: 1-cell - 9/9, 2-cell - 8/8, 4-cell - 10/10, 8-cell - 7/8, 16-cell - 8/8, morulae - 6/6, blastocysts - 8/8; RFF, 1-cell - 10/10, 2-cell - 8/8, 4-cell - 9/10, 8-cell - 10/10, 16-cell - 9/9, morulae - 7/7, blastocysts - 6/6; RFF-NaBu: 1-cell - 12/14, 2-cell - 9/9, 4-cell - 12/12, 8-cell - 10/10, 16-cell - 9/11, morulae - 9/9, blastocysts $-7 / 7$ ). All images except of 'Normal-Bl' are at magnification $\times 400$. Images of 'Normal-Bl' are at magnification $\times 200$.

pregnancy at the third week of gestation. The other recipient was operated on day 30 , and two live pups as well as one resorbed conceptus were delivered. The body weights of the pups were 96 and $54 \mathrm{~g}$ respectively. The placenta of the oversized pup was twofold larger than that of the 54 g-weight pup. The overgrown pup died $2 \mathrm{~h}$ after birth; the other appeared clinically healthy but died at the age of 2 weeks by an accident when leaving the nest of a foster mother. Post-mortem analysis showed that the overgrown pup had a number of abnormalities including a 'bulldog' phenotype, absence of normal skin pigmentation, swollen limbs and an enlarged liver. The pup, which has died accidentally, had no obvious abnormalities. Genetic analysis revealed that donor cells, tissue samples from placentas and pups were all Ali/Bas origin, but samples from recipient mother and a resorbed fetus showed no Ali/Bas genotype.

\section{Discussion}

Epigenetic reprogramming occurs abnormally in a large proportion of cloned embryos (Dean et al. 2001, Kang et al. 2003, Santos et al. 2003, Hiendleder et al. 2004, Wee et al. 2006) and is apparently species-specific (Dean et al. 2001, Beaujean et al. 2004a, 2004b, Shi et al. 2004) and largely dependent on the type of donor cells (Santos et al. 2003). Epigenetic marks, which characterize specific DNA and chromatin modifications, are the main players in nuclear reprogramming and can be used to assess this process and predict SCNT efficiency.

Embryos cloned from RFFs showed similar development to blastocyst as those cloned from RCCs (33 vs 34\%, $P>0.05)$. Our data do not confirm results from previous studies, in which cumulus cells were found to be better (Cervera \& Garcia-Ximenez 2003) or worse nuclear 
Table 2 Development of rabbit embryos cloned from NaBu-RFF after aggregation with blastomeres of in vitro fertilized or parthenogenetic embryos.

\begin{tabular}{|c|c|c|c|c|c|c|c|c|}
\hline \multirow[b]{2}{*}{ Embryo type } & \multirow[b]{2}{*}{$n$} & \multirow[b]{2}{*}{ Fused $(\%)$} & \multicolumn{3}{|c|}{ In vitro development } & \multicolumn{3}{|c|}{ In vivo development } \\
\hline & & & Cleaved (\%) & 4-cell (\%) & Blastocyst $(\%)^{\mathrm{a}}$ & $\begin{array}{l}\text { Embryos/ } \\
\text { recipients }\end{array}$ & Pregnancy & Offspring \\
\hline Cloned-2FB & 6 & $354 / 361(98)^{*}$ & $331 / 343(97)^{*}$ & $252 / 343(74)^{*}$ & $44 / 51(86)^{*}$ & $201 / 5$ & $2 / 5$ & 0 \\
\hline Cloned-1FB & 6 & $317 / 331(96)^{*}$ & $269 / 306(88)^{+}$ & $242 / 306(79)^{* \dagger}$ & $35 / 51(69)^{+}$ & $191 / 6$ & $1 / 6$ & 0 \\
\hline Cloned-2 PB & 6 & $277 / 281(99)^{*}$ & $237 / 275(86)^{\dagger}$ & $166 / 275(60)^{\ddagger}$ & $50 / 71(70)^{+}$ & $95 / 3$ & $0 / 3$ & 0 \\
\hline Cloned-1 PB & 6 & $359 / 367(98)^{*}$ & $289 / 346(84)^{\dagger}$ & $216 / 346(62)^{\ddagger}$ & $62 / 107(58)^{\ddagger}$ & $109 / 3$ & $2 / 3$ & 2 \\
\hline Cloned & 6 & $493 / 500(99)^{*}$ & $457 / 469(97)^{*}$ & $394 / 469(84)^{*}$ & $75 / 123(61)^{\ddagger}$ & $271 / 7$ & $1 / 7$ & 0 \\
\hline
\end{tabular}

Cloned, cloned embryos derived from NaBu-treated RFF; 1FB, 2FB, aggregated with 1 or 2 blastomeres of 6-12-cell fertilized embryos; 1PB, 2PB, aggregated with 1 or 2 blastomeres of $6-12$-cell parthenogenetic embryos. ${ }^{* \pm}$ Values within the same column with different superscripts differ significantly $(P<0.05)$. After aggregation with $\mathrm{FB}$ or $\mathrm{PB}$, the majority of embryos were transferred after 1 day of culture, but some were cultured up to day 5 and developed to blastocysts.

a Blastocyst rate was calculated relative to 4-cell stage embryos.

donors (Liu et al. 2004) as compared to fibroblasts. These differences might be due to the respective nuclear transfer protocol used in either study. In our study, after transfer into recipients, a higher pregnancy rate was obtained with embryos cloned from RCCs than with RFF-derived embryos. However, in vivo development of embryos cloned with either cell type was almost always limited to the middle of gestation, suggesting that other donor cell type-independent factors may impair embryonic development in the second period of gestation. Previous study in mouse showed that cloned embryos derived from cumulus cells developed better both in vitro and in vivo than those originating from fibroblasts (Wakayama \& Yanagimachi 2001). These results indicate that some intrinsic differences (e.g. differences in epigenetic status) may exist between these two cell types but could be species-specific.

Further, we tested whether two types of donor cells differ in the status of histone acetylation. We found significantly higher $(P<0.05)$ levels of acH3K9/14 in RCCs than in RFFs suggesting different organization of the chromatin of these cells. Treatment of RFFs with $\mathrm{NaBu}$ prior to nuclear transfer markedly increased the level of acH3K9/14 and this effect was associated with improved development of SCNT embryos in vitro. Thus, it is reasonable to suppose that the levels of acetylated histones in donor nuclei may affect their reprogramming after nuclear transfer.

A positive effect of $\mathrm{NaBu}$-treatment of donor fibroblasts was already observed in our previous studies on bovine SCNT, although no change in histone acetylation levels of donor cells could be detected by Western blot analysis (Shi et al. 2003a), suggesting that even subtle changes in histone acetylation levels are beneficial or that $\mathrm{NaBu}$ has other effects rendering donor cells more suitable for reprogramming. Unlike in bovine, where treatment of fetal fibroblasts with $\mathrm{NaBu}$ significantly increased both cleavage and blastocysts rates (Shi et al. 2003a), NaButreatment of RFFs markedly improved only blastocyst rate corroborating the notion that epigenetic reprogramming occurs late in rabbit compared to other species (Shi et al. 2004, Young \& Beaujean 2004).
We have demonstrated previously that epigenetic changes to the chromatin of donor cells including DNA methylation and histone methylation/acetylation can be reasonable marks of nuclear reprogramming, which correlate with developmental potential of cloned bovine embryos (Santos et al. 2003). In this study, NaBu-treated RFFs and RCCs exhibited higher levels of histone acetylation than non-treated RFFs correlating well with the greatest pre- or postimplantation developmental potential of cloned embryos respectively. Thus, the histone acetylation pattern of donor cells may be a useful mark to predict in vitro or in vivo development of nuclear transfer embryos in rabbits.

Although NaBu-treatment significantly improved development of embryos cloned from RFF-NaBu cells to blastocyst, their postimplantation development was not better compared to embryos derived from untreated cells. Likewise, embryos cloned from rabbit bone marrow cells, which showed the greatest rate of blastocysts $(60 \%)$, almost always failed to develop to term giving birth to only one cloned rabbit (Zakhartchenko et al. unpublished observations). It appears that development to blastocyst does not indicate proper reprogramming of the genome of a donor cell as does full-term development. Further, an increased level of acetylated histones in donor cells may not necessarily be followed by appropriate reprogramming after nuclear transfer. This suggests that the beneficial effect of enhanced histone acetylation may be overlapped by the defects in other epigenetic marking systems. In our recent study on methylation reprogramming (Shi et al. 2004), we showed that in vivo fertilized and cloned preimplantation rabbit embryos lack detectable methylation changes suggesting that genome-wide demethylation is not obligatory requirement for epigenetic reprogramming in this species. Moreover, the methylation patterns of embryos cloned from either cumulus or fibroblast cells were similar to those of in vivo embryos indicating that genome-wide DNA methylation is probably not a useful mark to assess nuclear reprogramming during cloning in rabbits. The proper reprogramming following nuclear transfer appears to be greatly 
dependent on multiple epigenetic modifications, which are affected by a number of crucial factors one of these is the cell cycle stage of a donor nucleus.

Recently, Li et al. (2006) reported a higher blastocyst rate with serum-starved than with confluent rabbit fibroblasts (46 vs $21 \%$ ) attributing this effect to synchronizing the cells in an inactive G0/G1 cell cycle phase. Moreover, after transfer of embryos cloned from serum-starved fibroblasts into recipients, 14 pups have been obtained and three of them survived. This study contrasts to our observations when we obtained the same proportions of embryos developing to blastocysts using serum-starved or confluent fetal fibroblasts (33 and 33\%, Zakhartchenko et al. unpublished observations). Although it is not more likely, but the two major differences, outbreed Zika vs inbreed New Zealand White rabbits, and fetal vs adult fibroblasts, could contribute to the discrepancy in the results. As to the effect of cell cycle synchronization, previous studies in several species demonstrated that, after culture to confluence or serum starvation, the majority of the cells are in G0/G1 phase of the cell cycle (Wilmut et al. 1997, Cibelli et al. 1998, Golzio et al. 2002, Shi et al. 2003a, Liu et al. 2004). For example, Dinnyes et al. (2001) showed that both starved and confluent rabbit fibroblasts have very similar proportions of G0/G1 and S phase cells (89 and $91 \%$, and 2 and $2 \%$ respectively), which differ significantly from those of cycling cells (60 and $11 \%$ respectively). In the present study, we have omitted cycling RFFs cells because of an increased proportion of such cells is in S-phase and do not work for NT. Previously we demonstrated that efficiency of NT was significantly lower with cycling than with serum-starved (30 vs $68 \%$ morulae/blastocysts, Galat et al. 2002) or confluent fibroblast cells (10 vs 33\% blastocysts, Zakhartchenko et al. unpublished observations).

$\mathrm{NaBu}$-treatment also influences the cell cycle by increasing the proportions of G0/G1 cells (cycling bovine epithelial cells, non-treated vs $\mathrm{NaBu}$-treated cells, 48 and 65\%, Shi et al. 2003a; human carcinoma cells, non-treated vs NaBu-treated cells, 59 and $72 \%$, Bartova et al. 2005; mouse fibroblasts, non-treated vs $\mathrm{NaBu}$-treated cells, 47 and $62 \%$, Matheu et al. 2005) but this effect is not so great as with serum starvation or culture to confluence. This suggests that the major effect of $\mathrm{NaBu}$, as an inhibitor of histone deacetylases, is dynamic reorganization of chromatin with changes in its epigenetic modifications.

Considering the fact that embryos cloned from RFF$\mathrm{NaBu}$ cells and RCCs showed the greatest pre- or postimplantation developmental potential, it was reasonable to expect that these embryos would be more similar to in vivo fertilized embryos in respect to the patterns of acH3K9/14 than those cloned from non-treated RFFs. The distribution of signals for acH3K9/14 in either group of cloned embryos did not resemble that in in vivo fertilized embryos. Although both in vivo fertilized and cloned embryos in either group showed a reduction of acH3K9/14 intensity at the 8-cell stage, most dramatical reduction of acH3K9/14 intensity was observed at the 8-cell stage in embryos cloned from RFF and RFF-NaBu cells. Nevertheless, the RCC group exhibited more similarities in acH3K9/14 patterns to the in vivo fertilized group than other two groups of cloned embryos. The fact that only NT with RCCs directly resulted in production of a cloned rabbit suggests that reprogramming occurs more easily with this type of cells. Surprisingly, acH3K9/14 signals of in vivo fertilized rabbit embryos were enhanced at the 4-cell stage but not at the 8-cell stage at which the rabbit embryonic genome activation occurs (Kanka et al. 1996, Henrion et al. 2000, Brunet-Simon et al. 2001). However, initiation of mRNA synthesis determined by in situ hybridization with a poly $(\mathrm{U})$ probe was first detectable at the late 2-cell stage (Kanka et al. 1993) and autoradiographically detectable initiation of transcription from an embryonic rabbit genome occurs at the 4-cell stage (Christians et al. 1994). An intense transcription then starts after the 8-cell stage and includes the onset of rRNA transcription (Kanka et al. 1996). Thus, enhanced levels of acH3H9/14 observed in our study at the 4-cell stage of in vivo fertilized and cloned embryos could be due to initiation of embryonic genome activation.

In the present study, we tested different types of blastomeres for aggregation with embryos cloned from $\mathrm{NaBu}$-treated RFF, which exhibited the greatest potential to develop to blastocyst in vitro. When cloned embryos were aggregated with blastomeres from in vivo fertilized embryos, none of the resulting fetuses and concepti were genetically identical to the nuclear donor cells. Blastomeres of cloned embryos were obviously not competitive with blastomeres of in vivo fertilized embryos corroborating the observations of Chrenek \& Makarevich (2005) when only $14 \%$ of SCNT blastomeres were present in the ICM of chimeric blastocyts obtained after their aggregation with blastomeres of in vivo embryos. Thus, we used a less competitive partner for aggregation that might nevertheless support implantation and postimplantation development of cloned embryos. It is well documented that mammalian parthenogenetic embryos do not develop to term because of deficient expression of maternal imprinted genes and are characterized by poor development of their extraembryonic membranes (Surani et al. 1986, 1990). Parthenogenetic rabbit embryos have the potential to implant but die near midgestation (Ozil 1990), and mouse parthenogenotes were used to assist the development to term of single blastomeres from 4-cell mouse embryos (Pinyopummin et al. 1994). Taking into account these facts, we performed aggregation of cloned embryos with parthenogenetic blastomeres. Although the development of these cloned embryos, aggregated with a single parthenogenetic blastomere, to blastocyst was similar to that of non-aggregated cloned embryos (58 vs $61 \%$ ), two clone-parthenote aggregates developed to term. 
Genotypic analyses confirmed that both pups were genetically identical with the Ali/Bas RFF donor cells. It is worth noting that we were unable to produce offspring either after transfer of embryos cloned from RFF-NaBu cells or RFF-derived embryos aggregated with pathenogenetic blastomeres (data not shown). This may indicate a positive effect of combination of $\mathrm{NaBu}$-treatment and chimeric embryo complementation.

It could be suggested that the two rabbits produced after complementation of cloned embryos with one parthenogenetic blastomere are chimeric. Even though parthenogenetic embryos die shortly after implantation, their cells are capable of participating in normal development of chimeras when aggregated with fertilized embryos (Fundele et al. 1989, Nagy et al. 1989, Allen et al. 1995, Boediono et al. 1999). Parthenogenetic cells were detected in some organs and tissues of adult chimeras. However, these cells were under severe selective pressure between days 13 and 15 of mouse development compared with cells from normal mouse fertilized embryos (Fundele et al. 1990). In the majority of chimeras, parthenogenetic cells in individual animals were observed in a limited number of tissues and organs and, even in these instances, their contribution was substantially reduced. Detection of any chimerism would require a genetic marker in the parthenogenetic cells, which was unfortunately not the case in this study. However, the use of genetically labeled nuclear donor cells clearly demonstrated that both cloned rabbit pups originated from these cells.

The overall efficiency of SCNT in our study based on the specific experiment that resulted in one live kit is $0.9 \%$ (one kit from 109 cloned embryos transferred) and similar or slightly lower compared to that reported by Chesne et al. $(1 \%, 4 / 371 ; 2002)$ and $\mathrm{Li}$ et al. (3\%, 14/467; 2006) respectively. We obtained a slightly higher efficiency of rabbit cloning with embryonic donor cells $(3 \%$, 8/284; Zakhartchenko et al. unpublished observations). This efficiency is similar to those obtained by Stice \& Robl $(4 \%, 1988)$ or by Yang et al. $(3 \%, 1992)$ providing evidence that the basic rabbit cloning procedure does work in our laboratory. Our control experiment with transfer of in vivo fertilized embryos proves the reliability of the applied embryo transfer technique.

In summary, our study demonstrates that although rabbit cumulus and fibroblast cells differ in the levels of acH3K9/14, the embryos cloned from either type of these cells show similar developmental potential in vitro. The levels of histone acetylation in donor cells can be modified by treatment with $\mathrm{NaBu}$ resulting in improved development of cloned embryos to blastocyst but not to term. Neither embryos cloned from RCC nor from RFF or RFF-NaBu cells entirely resembled the patterns of acH3K9/14 of in vivo fertilized embryos, suggesting that reprogramming of this epigenetic mark is aberrant in cloned rabbit embryos and cannot be corrected by treatment of donor cells with a HDAC inhibitor. However, RCCs seem to be better nuclear donors because of RCC-derived cloned embryos, which are more similar to in vivo fertilized embryos in respect to acH3K9/14 patterns than other two groups of cloned embryos, gave rise to a cloned pup without any assistant approaches. Production of live clones from RFFs required treatment of these cells with $\mathrm{NaBu}$ and chimeric embryo complementation with parthenogenetic blastomeres. This suggests that reprogramming occurs more abnormally with RFFs than with RCCs. Levels of acetylated histones, at least acH3K9/14, in donor cells and cloned embryos correlate with their developmental potential and may be a useful epigenetic mark to predict efficiency of NT. Cloning of rabbits from cultured donor cells provides the basis for further development of SCNT in this species, which would have a plethora of important applications in biomedicine and biotechnology.

\section{Acknowledgements}

We would like to thank Dr Josef Platzer, Therapeutic Human Polyclonals, Inc., for his support in the genetic confirmation of cloned rabbit embryos, fetuses, and offspring. This work was supported by a grant from the Bayerische Forschungsstiftung (478/01) and by Therapeutic Human Polyclonals, Inc. The authors declare that there is no conflict of interest that would prejudice the impartiality of this scientific work.

\section{References}

Allen N, Logan K, Lally G, Drage D, Norris M \& Keverne E 1995 Distribution of parthenogenetic cells in the mouse brain and their influence on brain development and behaviour. PNAS 92 10782-10786.

Baguisi A, Behboodi E, Melikan D, Pollock J, Destrempes $M$, Cammuso C, Williams J, Nims S, Porter C, Midura P et al. 1999 Production of goats by somatic cell nuclear transfer. Nature Biotechnology 17 456-461.

Bartova E, Pachernik J, Harnicarova A, Kovank A, Kovankova M, Hofmanova J, Skalnikova M, Kozubek M \& Kozubek S 2005 Nuclear levels and patterns of histone $\mathrm{H} 3$ modification and HP1 proteins after inhibition of histone deacetylases. Journal of Cell Science $\mathbf{1 1 8}$ 5035-5046.

Beaujean N, Hartshorne G, Cavilla J, Taylor J, Gardner J, Wilmut I, Meehan R \& Young L 2004a Non-conservation of mammalian preimplantation methylation dynamics. Current Biology 14 266-267.

Beaujean N, Taylor J, Gardner J, Wilmut I, Meehan R \& Young L 2004b Effect of limited DNA methylation reprogramming in the normal sheep embryo on somatic cell nuclear transfer. Biology of Reproduction 71 185-193.

Besenfelder U \& Brem G 1993 Laparoscopic embryo transfer in rabbits. Journal of Reproduction and Fertility 99 53-56.

Boediono A, Suzuki T \& Godke R 1999 Offspring born from chimeras reconstructed from parthenogenetic and in vitro fertilized bovine embryos. Molecular Reproduction and Development 53 159-170.

Brunet-Simon A, Henrion G, Renard G \& Duranthon V 2001 Onset of zygotic transcription and maternal transcript legacy in the rabbit embryo. Molecular Reproduction and Development 58 127-136. 
Cervera R \& Garcia-Ximenez F 2003 Oocyte age and nuclear donor cell type affect the technical efficiency of somatic cloning in rabbits. Zygote 11 151-158.

Challah-Jacques M, Chesne P \& Renard J 2003 Production of cloned rabbits by somatic nuclear transfer. Cloning and Stem Cells $\mathbf{5}$ 295-299.

Chesne P, Adenot P, Vigilietta C, Baratt M, Boulanger L \& Renard J 2002 Cloned rabbits produced by nuclear transfer from adult somatic cells. Nature Biotechnology 20 366-369.

Chrenek P \& Makarevich A 2005 Production of rabbit chimeric embryos by aggregation of zona-free nuclear transfer blastomeres. Zygote 13 39-44.

Christians E, Rao V \& Renard J 1994 Sequential acquisition of transcriptional control during early embryonic development in rabbits. Developmental Biology 164 160-172.

Cibelli J, Stice S, Golueke P, Kane J, Jerry J, Blackwell C, Ponce de Leon F \& Robl J 1998 Cloned transgenic calves produced from nonquiescent fetal fibroblasts. Science 280 1256-1258.

Dean W, Santos F, Stojkovic M, Zakhartchenko V, Walter J, Wolf E \& Reik W 2001 Conservation of methylation reprogramming in mammalian development: aberrant reprogramming in cloned embryos. PNAS 98 13734-13738.

Denning C \& Priddle H 2003 New frontiers in gene targeting and cloning: success, application and challenges in domestic animals and human embryonic stem cells. Reproduction 126 1-11.

Dinnyes A, Dai Y, Barber M, Liu L, Xu J, Zhou P \& Yang X 2001 Development of cloned embryos from adult rabbit fibroblasts: effect of activation treatment and donor cell preparation. Biology of Reproduction 64 257-263.

Ducibella T \& Anderson E 1975 Cell shape and membrane changes in the eight-cell mouse embryo: prerequisites for morphogenesis of the blastocyst. Developmental Biology 47 45-58.

Enright B, Jeong B, Yang X \& Tian X 2003a Epigenetic characteristics of bovine donor cells for nuclear transfer: levels of histone acetylation. Biology of Reproduction 69 1525-1530.

Enright B, Kubota C, Yang X \& Tian X 2003 b Epigenetic characteristics and development of embryos cloned from donor cells treated by trichostatin A or 5-aza-2'-deoxycytidine. Biology of Reproduction 69 896-901.

Fundele R, Norris M, Barton S, Reil W \& Surani A 1989 Systematic elimination of parthenogenetic cells in mouse chimeras. Development $10629-35$.

Fundele R, Norris M, Barton S, Fehlau M, Howlett S, Mills W \& Surani A 1990 Temporal and spatial selection against parthenogenetic cells during development of fetal chimeras. Development 108 203-211.

Galat V, Lagutina I, Melina M, Prokofiev M \& Zakhartchenko V 2002 Effect of donor cell age on the efficiency of nuclear transfer in rabbits. Reproductive Biomedicine Online 4 32-37.

Galli C, Lagutina I, Crotti G, Colleoni S, Turini P, Poderato N, Duchi R \& Lazzari G 2003 A cloned horse born to its dam twin. Nature 424635.

Garcia I, Brandt D, Benammar A, Cazenave P \& Jaton JC 1982 BASILEA rabbits express two types of immunoglobulin light chains: lambda and kappa-like. PNAS 79 4391-4394.

Golzio M, Teissie J \& Rols M 2002 Cell synchronization effect on mammalian cell permeabilization and gene delivery by electric field. Biochimica et Biophysica Acta 1563 23-28.

Henrion G, Renard J, Chesne P, Oudin J, Maniey D, Brunet A, Osborne H \& Duranthon V 2000 Differential regulation of the translation and the stability of two maternal transcripts in preimplantation rabbit embryos. Molecular Reproduction and Development 56 12-25.

Hiendleder S, Mund C, Reichenbach H-D, Wenigerkind H, Brem G, Zakhartchenko V, Lyko F \& Wolf E 2004 Tissue-specific elevated genomic cytosine methylation levels are associated with a overgrowth phenotype of bovine fetuses derived by in vitro techniques. Biology of Reproduction 71 217-223.
Inoue K, Ogonuki N, Yamamoto Y, Noguchi Y, Takeri S, Nakata S, Miki H, Kurome M, Nagashima H \& Ogura A 2002 Improved postimplantation development of rabbit nuclear transfer embryos by activation with inositol 1,4,5-trisphosphate. Cloning and Stem Cells 4 311-317.

Kang Y, Koo D, Park J, Choi Y, Chung A, Lee K \& Han Y 2001 Aberrant methylation of donor genome in cloned bovine embryos. Nature Genetics 28 173-177.

Kang Y, Lee K \& Han Y 2003 Reprogramming DNA methylation in the preimplantation stage: peeping with Dolly's eyes. Current Opinion in Cell Biology 15 290-295.

Kanka J, Flechon J \& Sutovsky P 1993 Onset of RNA synthesis and poly (A) content of early rabbit embryos. Comparison with sheep. Reproduction, Nutrition, Development 33 465-474.

Kanka J, Hozak P, Heyman Y, Chesne P, Degrolard J, Renard J \& Flechon J 1996 Transcriptional activity and nuclear ultrastructure of embryonic rabbit nuclei after transplantation to enucleated acolytes. Molecular Reproduction and Development 43 135-144.

Kato Y, Tani T, Sotomaru Y, Kurokawa K, Kato J, Doguchi H, Yasue H \& Tsunoda Y 1998 Eight calves cloned from somatic cells of a single adult. Science 282 2095-2098.

Kelus A \& Weiss S 1986 Mutation affecting the expression of immunoglobulin variable regions in the rabbit. PNAS 83 4883-4886.

Kishigami S, Mizutani E, Ohta H, Hikichi T, Thuan NV, Wakayama S, Bui H \& Wakayama T 2006 Significant improvement of mouse cloning technique by treatment with trichostatin A after somatic nuclear transfer. Biochemical and Biophysical Research Communications 340 183-189.

Kuroiwa Y, Kasinathan P, Matsushita H, Sathiyaselan J, Sullivan E, Kakitani M, Tomizuka K, Ishida I \& Robl J 2004 Sequential targeting of the genes encoding immunoglobulin-mu and prion protein in cattle. Nature Genetics 36 775-780.

Lee BC, Kim MK, Jang G, Oh HJ, Yuda F, Kim HJ, Shamim MH, Kim JJ, Kang SK, Schatten G et al. 2005 Dogs cloned from adult somatic cells. Nature 436641.

Li S, Chen X, Fang Z, Shi J \& Sheng H 2006 Rabbits generated from fibroblasts through nuclear transfer. Reproduction 131 1085-1090.

Liu J, Sung L, Du F, Julian M, Jiang S, Barber M, Xu J, Tian X \& Yang X 2004 Differential development of rabbit embryos derived from parthenogenesis and nuclear transfer. Molecular Reproduction and Development 68 58-64.

Matheu A, Klatt P \& Serrano M 2005 Regulation of the INK4a/ARF lokus by histone deacetylase inhibitors. Journal of Biological Chemistry 280 42433-42441.

McCreath K, Howcroft J, Campbell K, Colman A, Schnieke A \& Kind A 2000 Production of gene-targeted sheep by nuclear transfer from cultured somatic cells. Nature 405 1066-1069.

Nagy A, Sass M \& Markkula M 1989 Systematic non-uniform distribution of parthenogenetic cells in adult mouse chimeras. Development 106 321-324.

Ozil J 1990 The parthenogenetic development of rabbit oocytes after repetitive pulsatile electrical stimulation. Development 109 117-127.

Pinyopummin A, Takahashi Y, Hishinuma M \& Kanagawa H 1994 Development of single blastomeres from 4-cell stage embryos after aggregation with parthenogenones in mice. Japanese Journal of Veterinary Research 42 119-126.

Pitts J \& Burk R 1976 Specificity of junctional communication between animal cells. Nature 264 762-764.

Polejaeva I, Chen S, Vaught T, Page R, Mullins J, Ball S, Dai Y, Boone J, Walker S, Ayares D et al. 2000 Cloned pigs produced by nuclear transfer from adult somatic cells. Nature 407 86-90.

Rice J \& Allis C 2001 Histone methylation versus histone acetylation: new insights into epigenetic regulation. Current Opinion in Cell Biology 13 263-273.

Santos F, Zakhartchenko V, Stojkovic M, Peters A, Jenuwein T, Wolf E, Reik W \& Dean W 2003 Epigenetic marking correlates with developmental potential in cloned bovine preimplantation embryos. Current Biology 13 1116-1121. 
Schnieke A, Kind A, Ritchie W, Mycock K, Scott A, Ritchie M, Wilmut I, Colman A \& Campbell K 1997 Human factor IX transgenic sheep produced by transfer of nuclei from transfected fetal fibroblasts. Science 278 2130-2133.

Shi W, Hoeflich A, Flaswinkel H, Stojkovic M, Wolf E \& Zakhartchenko V 2003a Induction of a senescent-like phenotype does not confer the ability of bovine immortal cells to support the development of nuclear transfer embryos. Biology of Reproduction 69 301-309.

Shi W, Zakhartchenko V \& Wolf E 2003 b Epigenetic reprogramming in mammalian nuclear transfer. Differentiation 71 91-113.

Shi W, Dirim F, Wolf E, Zakhartchenko V \& Haaf T 2004 Methylation reprogramming and chromosomal aneuploidy in in vivo fertilized and cloned rabbit preimplantation embryos. Biology of Reproduction 71 340-347.

Shin T, Kraemer D, Pryor J, Liu L, Rugila J, Howe L, Buck S, Murphy K, Lyons L \& Westhusin M 2002 A cat cloned by nuclear transplantation. Nature 415859.

Stice S \& Robl J 1988 Nuclear reprogramming in nuclear transplant rabbit embryos. Biology of Reproduction 39 657-664.

Surani M, Barton S \& Norris M 1986 Nuclear transplantation in the mouse: heritable differences between parental genomes after activation of the embryonic genome. Cell 45 127-136.

Surani M, Kothary R, Allen N, Singh P, Fundele R, Ferguson-Smith A \& Barton S 1990 Genome imprinting and development in the mouse. Development. Supplement 89-98.

Tian X, Kubota C, Enright B \& Yang X 2003 Cloning animals by somatic cell nuclear transfer-biological factors. Reproductive Biology and Endocrinology 198.

Turner B 2000 Histone acetylation and epigenetic code. BioEssays 22 836-845.

Wakayama T \& Yanagimachi R 2001 Mouse cloning with nucleus donor cells of different age and type. Molecular Reproduction and Development 58 376-383.

Wee G, Koo D, Song B, Kim J, Kang M, Moon S, Kang Y, Lee K \& Han Y 2006 Inheritable histone H4 acetylation of somatic chromatins in cloned embryos. Journal of Biological Chemistry 281 6048-6057.

Wilmut I, Schnieke A, McWhir J, Kind A \& Campbell K 1997 Viable offspring derived from fetal and adult mammalian cells. Nature $\mathbf{3 8 5}$ 810-813.

Woods G, White K, Vanderwall D, Li G, Aston K, Bunch T, Meerdo L \& Pate B 2003 A mule cloned from fetal cells by nuclear transfer. Science 3011063.

Yang X, Jiang S, Kovacs A \& Foote R 1992 Nuclear totipotency of cultured rabbit morulae to support full-term development following nuclear transfer. Biology of Reproduction 47 636-643.

Yin X, Tani T, Kato Y \& Tsunoda Y 2000 Development of rabbit parthenogenetic oocytes and nuclear-transferred oocytes receiving cultured cumulus cells. Theriogenology 54 1469-1476.

Yin X, Kato Y \& Tsunoda Y 2002 Effect of enucleation procedures and maturation conditions on the development of nuclear-transferred rabbit oocytes receiving male fibroblast cells. Reproduction 124 41-47.

Young L \& Beaujean N 2004 DNA methylation in the preimplantation embryo: the differing stories of the mouse and sheep. Animal Reproduction Science 82-83 61-78.

Zakhartchenko V, Durcova-Hills G, Stojkovic M, Schernthaner W, Prelle K, Steinborn R, Mueller M, Brem G \& Wolf E 1999 Effects of serum starvation and re-cloning on the efficiency of nuclear transfer using bovine fetal fibroblasts. Journal of Reproduction and Fertility 115 325-331.

Zhou Q, Renard J, Le Friec G, Brochard V, Beaujean N, Cherifi Y, Fraichard A \& Cozzi J 2003 Generation of fertile cloned rats by regulating oocyte activation. Science 3021179.

Received 5 April 2006

First decision 5 May 2006

Revised manuscript received 10 August 2006

Accepted 11 September 2006 